\title{
Serotonin Syndrome/Serotonin Toxicity
}

\author{
Cynthia Wright Talton, DNP, FNP-BC
}

Objective: This review of serotonin syndrome or serotonin toxicity covers the years 2014 to 2019 , including information on pathophysiology, etiology, and diagnosis, 3 criteria for diagnosing serotonin syndrome, and criteria for neuroleptic malignant syndrome.

Importance: The review highlights the potential lethal combinations of commonly prescribed medications used to treat both veteran and nonveteran patients and includes the latest information on offending medications.

Conclusions: Prevention of serotonin toxicity includes informed clinicians, patient education, careful prescribing and monitoring, and avoidance of multidrug regimens.
Cynthia Talton is a Nurse Practitioner in the Outpatient Mental Health Clinic at the Veterans Affairs Medical Center in Salem, Virginia. Correspondence: Cynthia Talton

(cynthia.talton@va.gov)

Fed Pract. 2020;37(10):452-459 doi:10.12788/fp.0042 $\sigma^{2}$ erotonin, or 5-hydroxytryptamine (5-HT), is a chemical neurotransmitter in the central and peripheral nervous systems that was discovered in 1940s. ${ }^{1}$ One of the most widely studied chemical messengers, serotonin influences many physiologic functions in humans, including regulation of mood, sleep-wake cycle, appetite suppression, memory, emesis, breathing, cognition, blood coagulation, libido, and many other functions. ${ }^{2}$ In 1992, Insel and colleagues first documented the toxic symptoms produced from too much serotonin in the central and peripheral nervous systems, naming it serotonin syndrome. . $^{3,4}$

\section{SEROTONIN SYNDROME}

Experts in the fields of psychiatry, pharmacy, and toxicology refer to these symptoms as serotonin toxicity, because the symptoms result from the toxic effects of too much serotonin..$^{5-9}$ The term toxicity instead of syndrome "clarifies that it is a form of poisoning, just as lithium toxicity is a form of poisoning." Therefore, serotonin toxicity (ST) can develop with administration of any serotoninenhancing medication, including therapeutic use, polypharmacy, or accidental/intentional drug overdose.

The incidence of ST has increased over the past decade. . $, 6,10,11$ Several reasons explain this increase: (1) ST mirrors the increase in depression in the US populations $^{10,12,13}$; (2) There has been an increase in off-label antidepressant prescribing by both primary care and mental health providers ${ }^{14-16}$; (3) the increased use of illicit drugs $^{13}$; (4) an increase in suicide attempts with antidepressants ${ }^{17}$; and (5) increased use of opioids for pain management, including both prescription and illicit use. ${ }^{11,14}$
This paper reviews the potential lethal combinations of commonly prescribed medications used to treat both veteran and nonveteran patients and includes the latest information on offending medications; a presentation of symptoms from in utero to adult; diagnostic criteria; and recommended treatments.

The Veterans Health Administration (VHA) and non-VHA health care providers can play a key role in identifying and preventing serotonin syndrome/ST by keeping abreast of the latest updates of potentially lethal drug combinations. Commonly prescribed medications with the potential for a reaction include antidepressants, anxiolytics, pain medications, antinausea medications, herbal medications, and over-the-counter (OTC) medications, such as cough suppressants. Patients may be at increased risk for ST due to the growth of polypharmacy management of comorbidities.

\section{Antidepressants}

Over the past decade, antidepressant use has increased substantially in the US, United Kingdom, and Canada. ${ }^{14}$ Also the types of antidepressants prescribed has changed and been replaced with the newer agents. The selective serotonin reuptake inhibitors (SSRIs) and selective norepinephrine reuptake inhibitors (SNRIs) have replaced the older tricyclics (TCAs) and monoamine oxidase inhibitors (MAOIs) as first-line treatments for depression due to their improved comparative efficacy, reduced mortality following overdose, adverse effects (AEs) that are more tolerable for most patients, and the SSRIs have no anticholinergic properties (except paroxetine) (Table 1). ${ }^{18}$ 
TABLE 1 Serotonin-Elevating Medications

\begin{tabular}{|c|c|c|c|c|c|}
\hline SRIs & SGA & Opioids & Illicit Drugs & ОTC/Herbals & Disputed ${ }^{a}$ \\
\hline $\begin{array}{l}\text { SSRIs } \\
\text { (es)citalopram }\end{array}$ & \multirow[t]{23}{*}{ Ziprasidone } & Meperidine & MDMA/Ecstasy & St. John's Wort & $\begin{array}{l}\text { Antidepressants } \\
\text { Amitriptyline }\end{array}$ \\
\hline Fluoxetine & & \multirow[t]{2}{*}{ Methadone } & \multirow[t]{2}{*}{ Cocaine } & \multirow[t]{2}{*}{ L-tryptophan } & Mirtazepine \\
\hline Fluvoxamine & & & & & Trazodone \\
\hline Paroxetine & & \multirow[t]{2}{*}{ Pentazocine } & \multirow[t]{2}{*}{ Amphetamines } & \multirow[t]{2}{*}{ Ginseng } & Nefazodone \\
\hline Sertraline & & & & & Bupropion \\
\hline Vilazodone & & Pethidine & Methamphetamine & Dextromethorphan & \\
\hline Vortioxetine & & \multirow[t]{6}{*}{ Tramadol } & Phentermine & \multirow{3}{*}{$\begin{array}{l}\text { S-adenosyl-L-methionine } \\
\text { (SAMe) }\end{array}$} & Antiemetics \\
\hline SNRIs & & & & & Ondansetron \\
\hline (des)venlafaxine & & & LSD (lysergic acid & & Metoclopramide \\
\hline Duloxetine & & & diethylamide) & Chlorpheniramine & \\
\hline \multirow{2}{*}{ (levo)milnacipran } & & & & & Tryptans \\
\hline & & & Bath salts & Brompheniramine & \\
\hline $\begin{array}{l}\text { TCAs } \\
\text { Clomipramine }\end{array}$ & & & & & Buspirone \\
\hline Imipramine & & & & & Olanzapine \\
\hline MAOIs & & & & & Lithium \\
\hline Moclobemide & & & & & \\
\hline Isocarboxazid & & & & & Fentanyl \\
\hline Phenelzine & & & & & \\
\hline Tranylcypromine & & & & & Methylphenidate \\
\hline Methylene blue & & & & & \\
\hline Linezolid (weak) & & & & & Cyclobenzaprine \\
\hline Isoniazid (weak) & & & & & \\
\hline Metaxolone (weak) & & & & & \\
\hline
\end{tabular}

Abbreviations: LSD, lysergic acid diethylamide; MAOIs, monoamine oxidase inhibitors; MDMA, methylenedioxymethamphetamine; OTC, over-the-counter; SGA, second-generation antipsychotics; SNRIs, selective norepinephrine reuptake inhibitors; SRI, serotonin reuptake inhibitor; SSRIs, selective serotonin reuptake inhibitors; TCAs, tricyclic antidepressants.

${ }^{a}$ Disputed-experts disagree on these medications causing serotonin syndrome/toxicity because of their mechanisms of action.

In 2017 the National Institute of Mental Health reported that about 17 million adults and 3 million adolescents (aged 11-18 years) experienced at least 1 episode of major depression. ${ }^{19}$ About $40 \%$ of US veterans will experience depression, which is 3 times higher than the rate of the general US population. ${ }^{12}$ A random sampling survey conducted of about 17,000 active-duty service members by the US Department of Defense (DoD) from November 2015 to April 2016 revealed 9.4\% reported depression..$^{20}$ Antidepressant usage in the US and among veterans continues to increase. ${ }^{12,16}$ In 2018, the list of top US prescribed drugs, included sertraline (14th), citalopram (2lst), trazodone (24th), and escitalopram (26th). ${ }^{21}$ Antidepressant prescribing in the US increased 18\% from 2012 to $2017 .{ }^{22}$ This trend also continues within the military with a $40 \%$ increase of antidepressant use in the past decade. ${ }^{16}$

One reason for the increase in antidepressant use is off-label prescribing. ${ }^{14,23} \mathrm{~A}$ sampling of about 2 billion psychiatric out- patient visits in a western portion of the US found $12.9 \%$ of the prescriptions filled were off-label. ${ }^{15}$ In Minnesota, off-label prescribing of antidepressants was found to contribute to an increase in drug interactions in elderly nursing home residents. ${ }^{24}$ An investigation by the Military Times of the military community revealed offlabel prescribing occurs not only with antidepressant medications, but also with anticonvulsants, antipsychotics, anti-anxiety drugs, and antiepileptic medications. ${ }^{14}$

A case report that brought ST to the forefront occurred in the 1980s and involved a college student. ${ }^{25}$ She was initially diagnosed with the flu. Her symptoms progressed over a 24-hour period despite treatment, leading to seizures, hyperthermia, generalized clonus, muscle rigidity, respiratory failure, and death because of unrecognized ST. Her combination of serotonin-elevating drugs included meperidine, phenelzine, chlorpheniramine, and haldol. On autopsy, there were traces of cocaine found in some of her tissue samples. 
TABLE 2 Drugs Causing Moderate to Severe ST Symtoms ${ }^{4}$

\begin{tabular}{|c|c|}
\hline Drug Classes & Drug Combinations \\
\hline MAOIs & $\begin{array}{l}\text { MAOIs + SSRIs or SNRIs or TCAs or opiates } \\
\text { Imipramine + tranylcypromine } \\
\text { Phenelzine + meperidine } \\
\text { Methylene blue + clomipramine or paroxetine }\end{array}$ \\
\hline SSRIs & $\begin{array}{l}\text { SSRIs + MAOIs or TCAs or SNRls or opiates or tryptans } \\
\text { Fluoxetine + carbamazepine or phentermine or fentanyl }\end{array}$ \\
\hline SNRIs & $\begin{array}{l}\text { SNRIs + TCAs or MAOls or opiates or triptans } \\
\text { Fluoxetine + mirtazapine or phentermine or fentanyl }\end{array}$ \\
\hline Other antidepressants & $\begin{array}{l}\text { Mirtazapine + SSRIs } \\
\text { Trazodone + amitriptyline + lithium }\end{array}$ \\
\hline Opiates & Opiates + MAOls or SSRIs or SNRIs or triptans \\
\hline Cold remedies & $\begin{array}{l}\text { Dextromethorphan }+ \text { SSRIs or TCAs or atypical } \\
\text { antipsychotics }\end{array}$ \\
\hline Atypical antipsychotics & $\begin{array}{l}\text { Olanzapine + citalopram and lithium } \\
\text { Risperidone + paroxetine or fluoxetine }\end{array}$ \\
\hline Antibiotics/antifungals & $\begin{array}{l}\text { Linezolid + SSRls or tapentadol } \\
\text { Fluconazole + citalopram } \\
\text { Ciprofloxacin + methadone + venlafaxine }\end{array}$ \\
\hline
\end{tabular}

Abbreviations: MAOls, monoamine oxidase inhibitors; SNRIs, selective norepinephrine reuptake inhibitors; SSRIs, selective serotonin reuptake inhibitors; ST, serotonin toxicity; TCAs, tricyclic antidepressants. depression with SSRIs, SNRIs, TCAs, and MAOIs. ${ }^{29}$ Three of the most studied receptors include $5-\mathrm{HT}_{\mathrm{IA}}, 5-\mathrm{HT}_{1 \mathrm{~B}}$, and $5-\mathrm{HT}_{2 \mathrm{~A}}$.

\section{Etiology}

Most serotonin-induced drug fatalities occur when combining serotonergic drugs that work through different pathways (Table 2)..$^{30}$ The most toxic combination of serotoninenhancing drugs includes MAOIs taken with SSRIs or SNRIs, or a combination of 2 MAOIs. ${ }^{5-9}$

Other potentially lethal combinations may include polypharmacy with antidepressants, pain medications, OTC medications, and illicit drugs. Linezolid, a new synthetic antimicrobial, is considered to be a weak MAOI. Therefore, prescribing it with other serotonin-elevating agents has been reported to precipitate $\mathrm{ST}^{18}$

Most cases of ST do not require hospitalization and can be managed by stopping the medication or decreasing the dose. Therapeutic doses of a single drug are highly unlikely to cause toxicity, although there have been reported cases of patients who are sensitive or more susceptible and develop symptoms after administration of a single agent and/or a dosage increase.

Delayed ST reactions have occurred because of a prolonged half-life of a drug, iron deficiency anemia, and coingestion of shorter acting serotonin antagonists. ${ }^{31}$ Most antidepressants have a short half-life ( $<24$ hours) except for fluoxetine. A decrease in iron may contribute to ST because iron is needed to process serotonin from tryptophan. An example of 2 shorter-acting serotonin antagonists include cyproheptadine and olanzapine. Cyproheptadine is used in the treatment of ST, and olanzapine is an antipsychotic.

\section{SYMPTOMS}

Symptoms of ST range from mild to severe and include a combination of neuromuscular, autonomic, and mental status changes (Table 3). ${ }^{5,10}$ Mild symptoms of ST can start within 1 to 2 hours after ingesting a medication that increases serotonin to a toxic state unless the drug has a long half-life (eg, fluoxetine). Sometimes mild symptoms of ST can be difficult to distinguish from common drug AEs, flu symptoms, or viruses. Patients taking therapeutic doses of SSRIs 
can experience serotonin symptoms, such as lower limb hyperreflexia or a few beats of ankle clonus without being toxic. One thing to remember is that not all patients will start with mild symptoms and may present in moderate or severe distress.

Moderate-to-severe ST symptoms require hospitalization, usually in the intensive care unit (ICU). At this stage, clonus progresses from the lower extremities to the upper body and becomes more generalized. Ocular clonus can be continuous, intermittent, or have a ping pong effect (short cycle, periodic, alternating lateral gaze).

Severe ST is life threatening and leads to multiorgan failure within hours if not treated. The patient is intubated to assist with breathing and sedated because excess agitation and muscular tremors can increase temperature, which is already elevated by the time the symptoms reach the severe state. Of note, hyperthermia is due to a noninfectious elevation of body temperature from hypertonicity, agitation, and muscle rigidity. A true core temperature $>105.8^{\circ} \mathrm{F}$ causes irreversible cell damage, cerebral injury, and death. ${ }^{32,33}$ The patient can develop seizures and a coma. Multiorgan failure occurs, including rhabdomyolysis, myoglobinuria, renal failure, metabolic acidosis, acute respiratory distress, and disseminated intravascular coagulation.

\section{DIAGNOSIS}

The diagnosis of ST is clinical and based on a history of ingesting serotonin-elevating medications and physical findings as per Hunter Serotonin Toxicity Criteria ${ }^{34}$ (Table 4). An indepth history needs to include previous and current prescriptions, indications of the prescriptions (eg, therapeutic, increase in dosage, suicide intent), OTC medications, and illicit drug use. Early recognition of symptoms, identification of serotonergic medications, and appropriate resuscitative measures lead to more successful outcomes. A serotonin drug level is ineffective and does not correlate with the dosage since serotonin does not cross the blood-brain barrier.

The type of drug determines the length and response of the episode. The drug(s) elimination half-lives need to be calculated along with the pharmacokinetic or pharmacodynamics; agonist, antagonist, reuptake inhibitor, etc. Many drugs have half-lives of
TABLE 3 Serotonin Toxicity Signs/Symptoms ${ }^{5,10}$

\begin{tabular}{lll} 
Mild & Moderate & Severe \\
\hline Tremors & Hyperreflexia & $\begin{array}{l}\text { Hyperthermia } \\
\left(>101.3^{\circ} \mathrm{F}\right)\end{array}$ \\
Incoordination & $\begin{array}{l}\text { Clonus: lower extremities with } \\
\text { generalized progression }\end{array}$ & $\begin{array}{l}\text { Hyper/hypotension } \\
\text { Restlessness }\end{array}$ \\
Meadaches & Myoclonus (muscle jerks) & Sustained clonus or rigidity \\
Insomnia & Ocular clonus & Confusion \\
Nausea & Shivering with teeth chattering & Delirium \\
Diarrhea & Agitation & Tonic-clonic seizures \\
Clonus of lower & Diaphoresis & Respiratory depression \\
extremities & Tachycardia & Rhabdomyolysis \\
& Dyspnea & \\
& Dilated pupils &
\end{tabular}

$<24$ hours; therefore, reducing or eliminating the offending $\operatorname{drug}(\mathrm{s})$ will result in a steady reduction of symptoms. Exceptions include medications with a longer activity, such as the irreversible MAOIs (eg, phenelzine, isocarboxazid) and drugs with a longer halflife, such as fluoxetine. These types of medications may have been stopped weeks earlier and may prolong reduction of symptoms.

When initiating or increasing SSRIs or SNRIs, there are common nontoxic AEs that are not consistent with ST, including anxiety, restlessness, and irritability that may last for 2 weeks. The difference in toxic vs nontoxic reactions are the timing and rapid progression of symptoms. The toxic symptoms will start within hours of ingesting the offending agents(s) and progress rapidly to severe symptoms within 24 hours. Therefore, it is imperative to review AEs with the patient and or caregiver, so they may act as their own advocate and seek immediate assistance.

\section{Differentials}

There are symptoms specific to ST that can be used to differentiate it from other conditions. These include hyperthermia, bilateral symmetric clonus (inducible, spontaneous, ocular), and hyperreflexia. These criteria form the basis for Hunter criteria.

Differential diagnoses to consider include neuroleptic malignant syndrome; antidepressant initiation AEs; antidepressant discontinuation syndrome; malignant hyperthermia; anticholinergic toxicity; 
TABLE 4 Hunter Criteria (Need 3 to Diagnose) ${ }^{27}$

\begin{tabular}{cl} 
Criteria & Descriptions \\
\hline 1 & Spontaneous clonus \\
2 & Inducible clonus AND agitation OR diaphoresis \\
3 & Ocular clonus AND agitation OR diaphoresis \\
4 & Tremor AND hyperreflexia \\
5 & Hypertonic AND temperature $>100.4^{\circ} \mathrm{F}$ AND \\
& ocular clonus OR inducible clonus
\end{tabular}

meningitis/encephalitis; sepsis; drug overdose; alcohol/benzodiazepine withdrawal; and preeclampsia. Neuroleptic malignant syndrome (NMS) is the disorder most often misdiagnosed as ST. Key elements that distinguish ST from NMS include the timing of the clinical course (NMS develops over days to weeks); the medications ingested (NMS from dopaminergic drugs); and the symptoms of NMS (bradyreflexia, bradykinesia, bradyphrenia, and no clonus). According to Gillman, serotonin toxicity is a manifestation of toxicity that is predictable and common with specific drug combinations, while NMS is a "rare idiosyncratic reaction to essentially normal doses and very rarely occurs after overdoses." ${ }^{35}$ Preeclampsia is a pregnancy complication that can mimic ST with symptoms of hypertension, clonus, and hyperreflexia. It has been estimated to complicate $2 \%$ to $8 \%$ of pregnancies and remains a principle cause of maternal and fetal morbidity and mortality. ${ }^{36,37}$

\section{TREATMENT}

Mild-to-moderate symptoms usually resolve on their own 1 to 3 days after decreasing or stopping the offending drug. The timing will depend on the half-life or active metabolites of the drug. Treatment is largely supportive and may require treatment for control of agitation with benzodiazepines and IV fluids for dehydration/hypotension. ${ }^{14}$ In cases not responding to supportive care, treatment with oral cyproheptadine is recommended. ${ }^{14}$

There are other medications that have been used in treatment such as olanzapine, chlorpromazine, propranolol, bromocriptine, dantrolene, droperidol, and haloperidol, but their efficacy is unproven and not recommended. ${ }^{10}$ Chlorpromazine can cause hypotension and increase hyperthermia. Propranolol has a long duration of action, may cause a prolonged hypotension, and can mask tachycardia that can be used to monitor the effectiveness of treatment. ${ }^{10}$ Bromocriptine is a serotonin agonist and may exacerbate symptoms. Dantrolene has no effect on survival in animal models. ${ }^{10}$ Droperidol and haloperidol can worsen hyperthermia by inhibiting sweating. ${ }^{38}$

Mechanical ventilation should be considered especially if muscle rigidity progresses and depressed respiratory function occurs. If the temperature starts to rise, immediate sedation, paralysis, mechanical ventilation, and cyproheptadine are administered. The overall goal is prevention of hyperthermia, which leads to multiorgan failure. A core temperature of $\geq 104^{\circ} \mathrm{F}$ is associated with neurologic cell death, and recovery is minimal. ${ }^{32}$ Consultation with an experienced toxicologist is strongly recommended. Antipyretics should not be used, because elevated temperature is centrally mediated from muscle rigidity. If presentation occurs within 1 hour, activated charcoal can be used for detoxification of potentially lethal amounts.

\section{Warning Label Controversies}

In 2006, the US Food and Drug Administration (FDA) issued an advisory warning against concurrently using a tryptan antimigraine drug and serotonin-mediated medications ${ }^{39}$ In 2018, a research team conducted a 14-year retrospective analysis on 20,000 patients who were coprescribed a tryptan drug with SSRIs or SNRIs. ${ }^{40}$ The study reported that the risk of ST was rare and suggested that the FDA reconsider their advisory. There are several other controversial medications with a ST FDA warning label due to their mechanisms of action and inaccurate case reports. ${ }^{41}$

\section{Human Poisonings}

Consistent with the 2017 American Association of Poison Control Centers Toxic Exposure report, antidepressants continue to be in the top 5 substance classes most frequently involved in human exposures. ${ }^{42}$ Most accidental ingestions of antidepressants occur in toddlers, whereas intentional ingestions are usually done by adolesents. ${ }^{43}$ Over the past 10 years, antidepressants are the No. 1 fastest growing category of human exposures in all age groups. ${ }^{42}$ 


\section{ST in the Pediatric Population}

ST in the pediatric population mirrors that in adults. Differences include the inability of the child to report symptoms, lack of clinician awareness, and reluctance of adolescents to disclose recreational drug use. Management is the same as for adults, including discontinuing the offending drug, supportive care, adequate sedation, oxygen, IV fluids, and continuous cardiac monitoring. Sedation is weight based for benzodiazepines. Mild-tomoderate reactions require admission for observation. Severe reactions require admission to the ICU.

There have been at least 4 published case reports of children aged $<6$ years with moderate-to-severe ST secondary to acute vilazodone ingestion. ${ }^{44}$ The dosages included 5.5 to $37 \mathrm{mg} / \mathrm{kg}$. All $4 \mathrm{pa}-$ tients had altered mental status, seizures, hyperthermia, mild clonus, tachycardia, and hypertension. They all survived with intensive care treatment, including intubation, sedation, cyproheptadine in 2 cases, activated charcoal and IV lorazepam in the other cases.

Direk and colleagues reported a case of a 12-year-old girl who was brought to the emergency department by her stepmother for seizurelike activity and was diagnosed with epilepsy and status epilepticus. ${ }^{45}$ In the pediatric ICU she developed tachycardia, fever, agitation, dilated pupils, tremors, increased deep tendon reflexes, spontaneous clonus, and horizontal ocular movements. A detailed clinical history was retaken and revealed that the child had been prescribed risperidone 1 week before by the psychiatric clinic due to behavioral problems, including stealing money, lying, and running away from home and school. On further investigation, the stepmother was taking clomipramine and discovered 9 missing pills.

\section{Pregnancy and Lactation}

The American College of Obstetricians and Gynecologists recommends that clinicians screen patients at least once during the perinatal period for depression and anxiety symptoms, using a standardized, validated tool and complete a full assessment of mood and emotional well-being during the postpartum, including screening for postpartum depression and anxiety with a validated in- strument. ${ }^{46}$ Treatment with antidepressants is controversial. "Current evidence is generally reassuring and indicates that the absolute risks of negative infant outcomes are small except for PNAS [poor neonatal adaptation syndrome], which largely appears to be selflimited." ${ }^{47}$ Antidepressants cross the human placenta and fetal blood-brain barrier. ${ }^{48} \mathrm{Sev}$ eral cases of infant toxicity from SSRIs have been reported with citalopram and escitalopram. ${ }^{49,50}$ Symptoms included severe muscle rigidity, lethargy, tachycardia, QTc prolongation, altered consciousness, hypertonia, and seizures at birth. These mothers had taken an SSRI during pregnancy.

\section{CONCLUSIONS}

This article highlights some of the latest information on ST. Increased awareness of all clinicians and their patients may help decrease unnecessary comorbidities and death. Early identification of ST symptoms will increase the chances for survival, because of the rapid progression of symptoms within 24 hours. Most fatal reactions occur when combining MAOIs with SSRIs, SNRIs, or another MAOI. Overdose with an SSRI does not progress to the severe symptoms unless combined with another serotoninelevating medication.

Education of all patients who are prescribed antidepressants must include awareness of the potential for serotonergic drug interactions, particularly from OTC medications, herbal medications, and illicit drugs. The diagnosis of ST is based on clinical findings and there must be a history of ingesting serotonin-elevating $\operatorname{drug}(\mathrm{s})$. Hunter Serotonin Toxicity Criteria is the gold standard for diagnosing symptoms along with consulting a toxicologist. Prevention of ST includes informed clinicians, patient education, careful prescribing and monitoring, and avoidance of multidrug regimens.

\section{Author disclosures}

The author reports no actual or potential conflicts of interest with regard to this article.

\section{Disclaimer}

The opinions expressed herein are those of the author and do not necessarily reflect those of Federal Practitioner, Frontline Medical Communications Inc., the US Government, or any of its agencies. This article may discuss unlabeled or investigational use of certain drugs. Please review the complete prescribing information for specific drugs or drug combinations-including indications, contraindications, warnings, and 
adverse effects-before administering pharmacologic therapy to patients.

\section{References}

1. Rapport MM, Green AA, Page IH. Serum vasoconstrictor, serotonin; isolation and characterization. J Biol Chem. 1948;176(3):1243-1251.

2. McCorvy JD, Roth BL. Structure and function of serotonin g protein coupled receptors. Pharmacol Ther. 2015;150:129-142. doi:10.1016/j.pharmthera. 2015.01.009

3. Insel TR, Roy BF, Cohen RM, Murphy DL. Possible development of serotonin syndrome in man. Am J Psychiatry. 1982;139(7):954-955. doi:10.1176/ajp.139.7.954

4. Scotton WJ, Hill LJ, Williams AC, Barnes NM. Serotonin syndrome: pathophysiology, clinical features, management, and potential future directions. Int $J$ Tryptophan Res. 2019;12:1-14. doi:10.1177/1178646919873925

5. Buckley N, Dawson AH, Isbister GK. Serotonin syndrome. BMJ. 2014;348:g1626. doi:10.1136/bmj.g1626

6. Gillman KP. Serotonin toxicity: introduction. https://psychotropical.com/serotonin-toxicity-introduction. Published November 13, 2014. Updated July 13, 2019. Accessed August 17, 2020.

7. Foong A-L, Patel T, Kellar J, Grindrod KA. The scoop on serotonin syndrome. Can Pharm J (OTT). 2018;151(4):233-239. doi:10.1177/1715163518779096

8. Foong A-L, Grindrod KA, Patel T, Kellar J. Demystifying serotonin syndrome (or serotonin toxicity). Can Fam Physician. 2018;64(10):720-727.

9. Gillman KP. Serotonin toxicity: summary. https://psychotropical.com/serotonin-toxicity-summary. Published November 13, 2014. Updated January 25,2018 . Accessed August 17, 2020.

10. Boyer EW. Serotonin syndrome (serotonin toxicity). https://www.uptodate.com/contents/serotonin -syndrome-serotonin-toxicity. Updated March 12, 2018. Access December 12, 2019.

11. Wang RZ, Vashistha V, Kaur S, Houchens NW. Serotonin syndrome: preventing, recognizing, and treating it. Cleve Clin J Med. 2016;83(11):810-817. doi:10.3949/ccjm.83a.15129

12. Walker T. The economic burden of depression among veterans. https://www.managedhealthcareexecutive .com/article/economic-burden-depression-among -veterans. Published November 9, 2018. Accessed August 17, 2020.

13. Substance Abuse and Mental Health Services Administration, Center for Behavioral Health Statistics and Quality. Key substance use and mental health indicators in the United States: results from the 2018 National Survey on Drug Use and Health (HHS Publication No. PEP195068, NSDUH Series H-54). Rockville, MD: Center for Behavioral Health Statistics and Quality, Substance Abuse and Mental Health Services Administration; 2019.

14. Wong J, Motulsky A, Abrahamowicz M, et al. Off label indications for antidepressants in primary care; descriptive study of prescriptions from an indication based electronic prescribing system. BMJ. 2017;356:j603. doi:org/10.1136/bmj.j603

15. Vijay A, Becker JE, Ross JS. Patterns and predictors of off-label prescription of psychiatric drugs. PLOS One. 2018;13(7):e0198363. doi:10.1371/journal.pone.0198363

16. Medicating the military-use of psychiatric drugs has spiked; concerns surface about suicide, other dangers. https://www.militarytimes.com/2013/03/29/medicating -the-military-use-of-psychiatric-drugs-has-spiked -concerns-surface-about-suicide-other-dangers. Published March 29, 2013. Accessed August 17, 2020.

17. Hengartner MP, Plöderl M. Newer-generation antidepressants and suicide risk in randomized controlled trials; a re-analysis of the FDA database [letter]. Psychother Psychosom. 2019:88:247-248. doi:10.1159/000501215

18. Rosebush PI. Serotonin syndrome. https://www.mhaus .org/nmsis/medical-education-programs/serotonin -syndrome. Accessed March 24, 2020.
19. National Institute of Mental Health. Major depression. https://www.nimh.nih.gov/health/statistics/major -depression.shtml. Updated February 2019. Accessed March 24, 2020

20. Meadows SO, Engel RL, Beckman RL, et al. 2015 health related behaviors survey: mental and emotional health among U.S. active-duty service members. https://www .rand.org/pubs/research_briefs/RB9955z3.html. Published 2018. Accessed August 17, 2020.

21. ClinCalc. The top 300 drugs of 2020 . https://clincalc .com/DrugStats/Top300Drugs.aspx. Update February 11 2017. Accessed March 24, 2020.

22. Corrigan C. Revealed: massive rise in antidepressant prescribing. https://www.rte.ie/news /investigations-unit/2019/0218/1031271-massive -rise-antidepressant-prescribing. Published June 14, 2019. Accessed August 17, 2020.

23. Skånland SS, Cieślar-Pobuda A. Off-label uses of drugs for depression. Eur J Pharmacol. 2019;865: 172732. doi:10.1016/j.ejphar.2019.172732

24. Bobo WV, Grossardt BR, Lapid MI, et al. Frequency and predictors of the potential overprescribing of antidepressants in elderly residents of a geographically defined U.S. population. Pharmacol Res Perspect. 2019;7(1):e00461. doi:10.1002/prp2.461

25. Patel N. Learning lessons. The Libby Zion case revisited. J Am Coll Cardiol. 2014;64(25):2802-2804. doi:10.1016/j.jacc.2014.11.007

26. Jenkins TA, Nguyen JCD, Polglase KE, Bertrand PP. Influence of tryptophan and serotonin on mood and cognition with a possible role of the gut-brain axis. Nutrients. 2016;8(1):56. doi:10.3390/nu8010056

27. Coleman JA, Green EM, Gouaux E. X-ray structures and mechanism of the human serotonin transporter. Nature Int J Sci. 2016;532(7599):334-339. doi:10.1038/nature17629

28. Garcia-Garcia AL, Newman-Tancredi A, Leonardo ED. 5-HT(1A) [corrected] receptors in mood and anxiety: recent insights into autoreceptor versus heteroreceptor function. Psychopharmacology (Berl). 2013;231(4):623636. doi:10.1007/s00213-013-3389-x

29. Nautiyal KM, Hen $R$. Serotonin receptors in depression: from A to B. F1000Res. 2017;6:123. doi:10.12688/f1000research.9736.1

30. Francescangeli J, Karamchandani K, Powell M, Bonavia A. The serotonin syndrome: from molecular mechanisms to clinical practice. Int J Mol Sci. 2019;20(9):2288. doi:10.3390/ijms20092288

31. Little K, Lin CM, Reynolds PM. Delayed serotonin syndrome in the setting of a mixed fluoxetine and serotonin antagonist overdose. Am J Case Rep. 2018;19:604-607. doi:10.12659/AJCR.909063

32. Walter EJ, Carraretto M. The neurological and cognitive consequences of hyperthermia. Crit Care. 2016;20:199. doi:10.1186/s13054-016-1376-4

33. Platt M, Price T. Heat illness. In: Walls, ed. Rosen's Emergency Medicine: Concepts and Clinical Practice. Philadelphia, PA: Elsevier; 2018:1755-1764.

34. Dunkley EJC, Isbister GK, Sibbritt D, Dawson AH, Whyte IM. The Hunter Serotonin Toxicity Criteria: simple and accurate diagnostic decision rules for serotonin toxicity. QJM. 2003;96(9):635-642. doi:10.1093/qjmed/hcg109

35. Gillman KP. Serotonin toxicity contrasted with neuroleptic malignant syndrome. https://psychotropical.com /serotonin-syndrome-and-neuroleptic-malignant -syndrome. Published January 1, 2005. Updated November 6, 2017. Accessed August 17, 2020.

36. Asusta HB, Keyser E, Dominguez P, Miller M, Odedokun T. Serotonin syndrome in obstetrics: a case report and review of management. Mil Med. 2018;184(1-2):e284e286. doi:10.1093/milmed/usy135

37. English FA, Kenny LC, McCarthy FP. Risk factors and effective management of preeclampsia. Integr Blood Press Control 2015;8:7-12. doi:10.2147/IBPC.S50641

38. Bruggeman C, O'Day CS. Selective serotonin reup- 
take inhibitor (SSRI) toxicity. https://pubmed.ncbi.nlm.nih .gov/30521236. Published December 3, 2019. Accessed August 17, 2020.

39. US Food and Drug Administration. Selective serotonin reuptake inhibitors (SSRIs) Information. https://www.fda. gov/drugs/information-drug-class/selective-serotoninreuptake-inhibitors-ssris-information. Updated December 23, 2014. Accessed March 24, 2020.

40. Orlova Y, Rizzoli P, Loder E. Association of coprescription of triptan antimigraine drugs and selective serotonin reuptake inhibitor or selective norepinephrine reuptake inhibitor antidepressants with serotonin syndrome. JAMA Neurol. 2018;75(5):566-572. doi:10.1001/jamaneurol.2017.5144

41. Gillman KP. Regulatory agencies (WHO, FDA) offer illconceived advice about serotonin toxicity (serotonin syndrome) with 5-HT3 antagonist: a worldwide problem. https://psychotropical.com/serotonin-toxicity-and-5-ht3 -antagonists. Published November 13, 2014. Updated March 23, 2019. Accessed August 17, 2020.

42. Gummin DD, Mowry JB, Spyker DA, Brooks DE, Osterthaler KM, Banner W. 2017 Annual Report of the American Association of Poison Control Centers' National Poison Data System (NPDS): 35th Annual Report. Clin Toxicol (Phila). 2018;56(12):1213-1415. doi:10.1080/15563650.2018.1533727

43. Badawy MK, Maffei FA. Pediatric selective serotonin reuptake inhibitor toxicity. https://emedicine.medscape .com/article/1011436. Updated September 27, 2019. Accessed August 17, 2020.
44. Laliberte B, Kishk OA. Serotonin syndrome in a pediatric patient after vilazodone ingestion. Pediatr Emerg Care. 2018;34(12):e226-e228. doi:10.1097/PEC.0000000000001115

45. Direk MC, Yildirim V, Günes S, Bozlu G, Okuyaz C. Serotonin syndrome after clomipramine overdose in a child. Clin Psychopharmacol Neurosci. 2016;14(4):388-390. doi:10.9758/cpn.2016.14.4.388

46. ACOG Committee Opinion No. 757: Screening for perinatal depression. Obstet Gynecol. 2018;132(5):e208e212. doi:10.1097/AOG.0000000000002927

47. Osborne LM, McEvoy K, Payne JL. Antidepressants in pregnancy: balancing needs and risks in clinical practice. Psychiatric Times. 2017;34(4).

48. Stewart D, Vigod S. Antenatal use of antidepressants and risk of teratogenicity and adverse pregnancy outcomes: selective serotonin reuptake inhibitors (SSRIs). https://www.uptodate.com/contents /antenatal-use-of-antidepressants-and-risk-of -teratogenicity-and-adverse-pregnancy-outcomes -selective-serotonin-reuptake-inhibitors-ssris. Accessed March 24, 2020.

49. Degiacomo J, Luedtke S. Neonatal toxicity from escitalopram use in utero: a case report. $J$ Pediatr Pharmacol Ther. 2016;21(6):522-526. doi:10.5863/1551-6776-21.6.522

50. Eleftheriou G, Butera R, Cottini FC, Bonati M, Farina $M$. Neonatal toxicity following maternal citalopram treatment. Fetal Pediatr Pathol. 2013;32(5):362-356. doi:10.3109/15513815.2013.768743 